\title{
Electrochemically active species in aluminum electrodeposition baths of $\mathrm{AlCl} / \mathrm{glyme}$ solutions
}

\section{$\operatorname{AUTHOR}(\mathrm{S}):$}

Kitada, Atsushi; Nakamura, Kai; Fukami, Kazuhiro; Murase, Kuniaki

\section{CITATION:}

Kitada, Atsushi ...[et al]. Electrochemically active species in aluminum electrodeposition baths of AlCl3/glyme solutions. Electrochimica Acta 2016, 211: 561-567

\section{ISSUE DATE:}

2016-09-01

URL:

http://hdl.handle.net/2433/255864

\section{RIGHT:}

(C) 2016. This manuscript version is made available under the CC-BY-NC-ND 4.0 license http://creativecommons.org/licenses/by-nc-nd/4.0/; この論文は出版社版でありません。 引用の際には出版社版をご確認ご利用ください。; This is not the published version.

Please cite only the published version. 
Electrochimica Acta

Elsevier Editorial system(tm) for

Manuscript Draft

Manuscript Number: ISE15-07-04R2

Title: Electrochemically Active Species in Aluminum Electrodeposition Baths of AlCl3/Glyme Solutions

Article Type: SI: 2015 ISE Mtg Taiwan

Keywords: Aluminum electrodeposition, Glyme, Raman spectroscopy, Electrochemically active species

Corresponding Author: Dr. Atsushi Kitada, Ph. D.

Corresponding Author's Institution: Kyoto University

First Author: Atsushi Kitada, Ph. D.

Order of Authors: Atsushi Kitada, Ph. D.; Kai Nakamura, Master; Kazuhiro Fukami, Ph. D.; Kuniaki Murase, Ph. D.

Manuscript Region of Origin: JAPAN

Abstract: Electrochemically active species in aluminum (Al) electrodeposition baths using AlCl3 and less volatile solvents i.e. glymes were investigated. Raman spectroscopy revealed that all the glyme baths contained AlCl4- anions and Al-Cl-glyme cations as ionic species. Room temperature conductivities were as high as the order of $10-3 \mathrm{~S} \mathrm{cm-1}$ for the diglyme (G2), triglyme (G3) and tetraglyme (G4) baths, whereas that for the butyl diglyme (butylg2) bath was only 10-4 S cm-1 due to a lower concentration of ionic species. Surprisingly, electrochemical measurements showed that, among the glyme baths, only the G2 bath enabled electrodeposition of Al. Consequently, despite the similar structures of Al-Cl-glyme complex cations, only the G2 complex cations are electrochemically active. This suggests that the desolvation of glymes from Al-Cl-glyme cations and their subsequent reduction is exceptionally easy for the G2 complexes. 
Dear Editor of Electrochimica Acta

We are submitting the revised version of the manuscript (ISE-15-07-04R1), titled "Electrochemically Active Species in Aluminum Electrodeposition Baths of $\mathrm{AlCl}_{3} / \mathrm{Glyme}$ Solutions". Labels of Graphs were amended to "Potential vs. Al (QRE) / V".

Our responses to the reviewer's suggestions are summarized as follows:

1. Introduction, Line 14: separate 'abovementioned' so it reads 'above mentioned'.

We corrected.

2.4 Bath characterization, Line 4: Were these measurements really performed in dry air or was an inert gas used?

We added the following sentence in lines 8-9 of 2.4: "The sample solutions were sealed under Ar with septum and then measured within an hour after taken out from a glove box."

3.5 Electrochemically active species, Lines 4-6: This text was taken word for word from my previous review. Since I am not listed as a co-author, I'd appreciate it if the authors used their own words.

In the revised manuscript we rewrote as "The sulfone-solvated $\mathrm{Al}^{3+}$ species are generated together with the formation of $\mathrm{AlCl}_{4}{ }^{-}$. Since the resource of $\mathrm{Cl}^{-}$is $\mathrm{AlCl}_{3}$, asymmetric cleavage of $\mathrm{AlCl}_{3}$ occurs to form $\mathrm{AlCl}_{4}{ }^{-}$and $\left[\mathrm{Al}(\text { sulfone })_{3}\right]^{3+} .$,

3.6 RT electrodeposition of Al, Lines 8-10: delete "essentially". Also, the way the sentence is written, it is not clear whether $\mathrm{Al} 2 \mathrm{O} 3$ was present as an impurity in the $-1.0 \mathrm{~V}$ electrodeposit.

We changed to "; in the case of potentiostatic electrodeposition at $-1 \mathrm{~V} v s$. Al QRE [47] the XRD profiles also show the deposits were crystalline Al.”.

Sincerely yours,

Atsushi Kitada, Ph. D

Department of Materials Science and Engineering, Kyoto University

Tel. +81-75-753-5475; Fax. +81-75-753-5463; E-mail kitada.atsushi.3r@kyoto-u.ac.jp 
1 2

Electrochemically Active Species in Aluminum Electrodeposition Baths of $\mathrm{AlCl}_{3} / \mathrm{Glyme}$ Solutions

\author{
Atsushi Kitada, Kai Nakamura, Kazuhiro Fukami, and Kuniaki Murase \\ Department of Materials Science and Engineering, Kyoto University, Kyoto 606-8501, Japan \\ E-mail: kitada.atsushi.3r@kyoto-u.ac.jp
}

\begin{abstract}
Electrochemically active species in aluminum (Al) electrodeposition baths using $\mathrm{AlCl}_{3}$ and less volatile solvents i.e. glymes were investigated. Raman spectroscopy revealed that all the glyme baths contained $\mathrm{AlCl}_{4}^{-}$anions and $\mathrm{Al}-\mathrm{Cl}$-glyme cations as ionic species. Room temperature conductivities were as high as the order of $10^{-3} \mathrm{~S} \mathrm{~cm}^{-1}$ for the diglyme (G2), triglyme (G3) and tetraglyme (G4) baths, whereas that for the butyl diglyme (butylG2) bath was only $10^{-4} \mathrm{~S} \mathrm{~cm}^{-1}$ due to a lower concentration of ionic species. Surprisingly, electrochemical measurements showed that, among the glyme baths, only the G2 bath enabled electrodeposition of Al. Consequently, despite the similar structures of Al-Cl-glyme complex cations, only the G2 complex cations are electrochemically active. This suggests that the desolvation of glymes from Al-Cl-glyme cations and their subsequent reduction is exceptionally easy for the $\mathrm{G} 2$ complexes.
\end{abstract}


Keywords: Aluminum electrodeposition, Glyme, Raman spectroscopy, Electrochemically active species

\section{Introduction}

Aluminum (Al) metal is essential for structural materials because of its low weight, workability, and corrosion resistance. Smelting of Al has been industrialized as the Hall-Héroult process: Al is electrowon from alumina-dissolved cryolite molten salt at $1000{ }^{\circ} \mathrm{C}$ [1]. Compared to this high temperature process, medium-low temperature electrodeposition is also of interest because it can be employed as a new Al-coating process. Various kinds of medium-low temperature bath for Al and Al-alloy electroplating have been reported [2]: they include organic solvents (e.g. ethers [3,4], aromatic hydrocarbons [5-9], sulfones [10-18] and others [19,20]), and ionic liquids [21-29], to name only a few. Some of them are applied to improve the corrosion resistance of magnesium alloys and steel [30-33]. Such Al electroplating baths are also attractive as a negative electrode material for next-generation “Al-ion” batteries because Al has low redox potential (-1.68 V vs. SHE) and

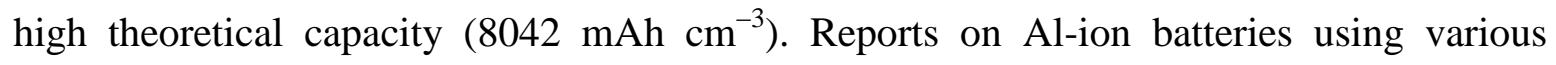
electrolytes including sulfones and ionic liquids have been presented [34-40]. However, the above-mentioned organic solvents are highly volatile at their electrodeposition temperatures including room temperature (RT). For example, there are RT sulfone baths to which toluene is added to make them liquid at $\mathrm{RT}$ and to improve the physical properties as $\mathrm{Al}$ electroplating baths $[39,40]$, but they become relatively volatile due to the addition of toluene. In addition, sulfur contamination of deposits has been reported in a sulfone system 
[17]. RT Ionic liquids are attractive for electroplating baths because they are thermally and chemically stable, less volatile and less flammable [21-29]. What is disadvantageous for ionic liquids, compared with organic solvents, is the high cost of the chemicals required for the bath preparation.

Safe and cheap alternatives to Al electroplating baths are of special interest. Very recently, glymes, i.e. glycol ethers, have drawn attention as relatively safe solvents for lithium and magnesium ion batteries, because they have boiling points above $150{ }^{\circ} \mathrm{C}$ and relatively low volatilities at RT [41-46]. In 2014 we published a communication paper on RT electrodeposition of $\mathrm{Al}$ using $\mathrm{AlCl}_{3}$ and glyme with the ratio $\mathrm{AlCl}_{3}$ :diglyme $(\mathrm{G} 2)=1: 5$ by mol, which was the first report for Al electroplating glyme baths [47]. Since then some fluorine-containing Al electrolytes with glymes were reported for Al redox at RT [48,49]; however, anodic dissolution in these fluorine-containing baths was difficult [48] and the redox current density was one-order of magnitude smaller compared to the $\mathrm{AlCl}_{3}-\mathrm{G} 2$ bath [49]. Moreover, the electrochemically active species in the $\mathrm{AlCl}_{3}-\mathrm{G} 2$ bath are still unknown and systematic study using other glymes has not been reported yet. Therefore, detailed and systematic study on $\mathrm{AlCl}_{3}$ /glyme baths is of interest. In this paper we discuss the electrochemical properties of $\mathrm{AlCl}_{3} /$ glyme solutions using four kinds of glymes as shown in Fig. 1. Somewhat surprisingly, electrodeposition was only successful from G2 solutions. Bath characterization and Raman spectroscopy indicated that only G2 can form electrochemically active complex cations, which can then undergo easy desolvation of the glymes and subsequent reduction of $\mathrm{Al}^{3+}$. 


\section{Experimental}

\subsection{Reagents}

Diglyme (G2; Diethyleneglycol dimethylether, electrochemistry grade, Kanto Chemical), triglyme (G3; triethyleneglycol dimethylether, 98.0\% purity, Tokyo Chemical Industry), tetraglyme (G4; tetraethyleneglycol dimethylether, 98.0\% purity, Tokyo Chemical Industry), and butyldiglyme (butylG2; diethyleneglycol dibutylether, 98.0\% purity, Tokyo Chemical Industry) were dried to less than 40 ppm $\mathrm{H}_{2} \mathrm{O}$ using $3 \mathrm{~A}$ molecular sieves before bath preparation.

\subsection{Bath preparation}

Each glyme solvent and as-received $\mathrm{AlCl}_{3}$ (Wako, 99.9\% purity) were mixed with glyme: $\mathrm{AlCl}_{3}$ at a 5:1 or 3:1 molar ratio with an agitation speed of $500 \mathrm{rpm}$. To dissolve $\mathrm{AlCl}_{3}$, the $\mathrm{G} 2$ mixture required heating at $65^{\circ} \mathrm{C}$ for $12 \mathrm{~h}$ while the other glyme solutions were obtained at $35^{\circ} \mathrm{C}$ for $1 \mathrm{~h}$. The bath preparation was conducted in an Ar-filled glovebox. The as-prepared solution contained 200 - 300 ppm water determined by Karl Fischer titration, probably due to some residual water in the $\mathrm{AlCl}_{3}$ reagent.

\subsection{Electrochemical measurements and characterization of deposits}

Electrochemical properties were measured in the Ar-filled glovebox with a potentiostat/galvanostat (Hokuto Denko, HSV-110). Measurements at RT were performed using a glass cell of $20 \mathrm{~cm}^{3}$ capacity where the planar dimension of WE was fixed to $7.5 \mathrm{~mm} \phi$ (EC Frontier, VM-2A) was utilized as reported in ref. 45, while a glass cell of $30 \mathrm{~cm}^{3}$ 
capacity was used for $\mathrm{CV}$ at elevated temperature and potentiostatic electrolysis. $\mathrm{Cu}$ sheet (Nilaco, 99.9\% purity, $0.080 \mathrm{~mm}$ thickness for CV, and Yamamoto-MS, B-60-P05, $0.30 \mathrm{~mm}$ thickness for electrolysis) and $\mathrm{Al}$ sheet (Nilaco, >99\% purity, $0.5 \mathrm{~mm}$ thickness) of size $1.0 \times$ $2.5 \mathrm{~cm}^{2}$ were used as working electrodes (WE). Al sheets of size $1.0 \times 2.0 \mathrm{~cm}^{2}$ were also used as a counter electrode $(\mathrm{CE})$ and a quasi-reference electrode $(\mathrm{QRE})$. The QRE was directly immersed in the same electrolyte. These electrodes were used for CV measurements after washing with acetone for $20 \mathrm{~min}$. Before the potentiostatic electrolysis, $\mathrm{Cu}$ WE was first washed with an alkaline soak cleaner (ACE CLEAN, Okuno Chemical), then with an aqueous etchant containing $100 \mathrm{~g} \mathrm{dm}^{-3} \mathrm{Na}_{2} \mathrm{~S}_{2} \mathrm{O}_{8}, 18 \mathrm{~g} \mathrm{dm}^{-3} \mathrm{H}_{2} \mathrm{SO}_{4}$, and $0.5 \mathrm{~g} \mathrm{dm}^{-3}$ $\mathrm{CuSO}_{4} \cdot 5 \mathrm{H}_{2} \mathrm{O}$, and finally with an activator (TOP SAN, Okuno Chemical). During the potentiostatic electrolysis, WE and CE were set to be parallel.

\subsection{Bath characterization}

Bath conductivity measurements were performed using Japan Machinery CDM230 and CDC749, and kinematic viscosity measurements were conducted using SEKONIC VM-10A calibrated using a standard solution (Nippon Grease Co., Ltd.). These measurements were performed in a dry-air-filled atmosphere at less than $40 \mathrm{ppm} \mathrm{H}_{2} \mathrm{O}$. Raman spectroscopy measurements were performed at RT using an integrated Raman system (B\&W Tek, innoRam 785) comprising a semiconductor laser light source $(785 \mathrm{~nm})$, a holographic probe head, an axial transmissive spectrograph, and a charge-coupled device (CCD) detector. The sample solutions were sealed under Ar with septum and then measured within an hour after taken out from a glove box. The spectral acquisition time, i.e., exposure time of CCD and the 
number of exposures was varied for each sample so as to improve the signal-to-noise ratio of each spectrum. In order to lessen the fluorescence as background intensity each glyme bath was measured after pre-electrolysis at $-1.0 \mathrm{~V} v s$. Al QRE for 1 or 2 days to obtain colorless solution. For the G3 and G4 baths the current densities during the pre-electrolysis were almost constant at approximately $0.1 \mathrm{~mA} \mathrm{~cm}^{-2}$.

\subsection{Characterization of electrodeposits}

After electrolysis the deposits were characterized by means of X-ray diffraction (XRD; Rigaku RINT2200; $40 \mathrm{kV}-30 \mathrm{~mA}, 0.4$ degree $\mathrm{min}^{-1}$ ) and scanning electron microscopy (SEM; Keyence VE-8800), in order to check the crystal orientation and surface morphology. Energy dispersive X-ray (EDX; EDAX Genesis 2000) and X-ray photoelectron spectroscopy (XPS; JEOL, JPS-9010TRX) were carried out to examine the contents and/or chemical states of $\mathrm{Al}$ and $\mathrm{Cl}$. The XPS was performed using a $\mathrm{Mg}-\mathrm{K} \alpha \mathrm{X}$-ray source with $\mathrm{Ar}^{+}$ion etching at a rate of approximately $18 \mathrm{~nm} \mathrm{~min}{ }^{-1}$, which was determined from a $\mathrm{SiO}_{2}$ standard film. The XPS spectra were calibrated assuming that the $\mathrm{C} 1 \mathrm{~s}$ peak position from hydrocarbons would be $285.0 \mathrm{eV}$. XPS, XRD and SEM observations were carried out for the deposits after washing with pure G2 and vacuum-drying.

\section{Results and Discussion}

3.1 Cyclic voltammetry 
Figure 2(a) shows the CVs for the glyme baths at RT, where $\mathrm{Cu}$ was used as WE. For the $\mathrm{G} 2$ bath, the onset potential of $\mathrm{Al}$ deposition was ca. $-0.7 \mathrm{~V} v s$. Al QRE, a reduction loop with the overpotential of ca. $0.2 \mathrm{~V}$ was observed, and the Coulombic efficiency was ca. $75 \%$. In addition, the dissolution of $\mathrm{Al}$ took place at a negative potential of $-0.2 \mathrm{~V}$, suggesting that the Al QRE have surface oxides to show a positive potential compared to the freshly deposited Al on WE. Similar negative shifts have been observed when Al QRE was directly immersed to the baths [22-24]. While large reduction currents and the corresponding oxidation currents (order of $\mathrm{mA} \mathrm{cm}^{-2}$ ) were observed for the $\mathrm{G} 2$ bath as reported previously [47], only small reduction currents of the order of $0.1 \mathrm{~mA} \mathrm{~cm}^{-2}$ were observed from near +0.5 $\mathrm{V}$ for the other glyme baths. With an onset potential of $+0.8 \mathrm{~V}$ a reversible but small oxidation and reduction current was observed in every glyme bath; this was attributed to $\mathrm{Cu}(\mathrm{I}) \mathrm{Cl}$ formation [47].

Figure 2(b) displays $\mathrm{CV}$ results for $\mathrm{Al} \mathrm{WE}$ at RT, where small cathodic overpotentials were anticipated and Al electrodeposition would occur even in the G3 and/or G4 baths. However, sizable reduction currents were observed only in the G2 bath. The onset potential was $-0.7 \mathrm{~V} v s$. Al QRE, similar to the case of $\mathrm{Cu}$ WE. The increase of potential in the G2 bath around $0 \mathrm{~V}$ is due to dissolution of deposited $\mathrm{Al}$ making an anodic wave that finished at about $+0.3 \mathrm{~V}$ or $+0.4 \mathrm{~V}$, followed by a sharper increase due to dissolution of the Al substrate. In the G3 and G4 baths, the cathodic currents were even smaller than in the case of Cu WE: as a result, there was no evidence of $\mathrm{Al}$ electrodeposition from $\mathrm{G} 3$ or $\mathrm{G} 4$ baths on either $\mathrm{Al}$ or $\mathrm{Cu}$ substrate. The observed anodic currents for the G3 and G4 baths with overpotentials of 
approximately $0.3 \mathrm{~V}$ was due only to dissolution of the Al substrate. We speculate that the small reduction currents correspond to the decomposition of impurities, not deposition of Al.

At elevated temperature the G2 bath showed larger redox currents than those at RT. Especially, a cathodic current of about $15 \mathrm{~mA} \mathrm{~cm}^{-2}$ was observed at $60{ }^{\circ} \mathrm{C}$. Up to $60{ }^{\circ} \mathrm{C}$ the redox currents became larger as temperature increases, and the bath properties also improved (see Table I). At $70{ }^{\circ} \mathrm{C}$, by contrast, the redox current was halved compared to that at $60{ }^{\circ} \mathrm{C}$ (see Fig. 2(c)). This may be related to the sample color being brown at $70{ }^{\circ} \mathrm{C}$, implying that thermal decomposition affects redox properties. CV measurements were also performed in the G3 and G4 baths at $60{ }^{\circ} \mathrm{C}$. Compared with those at RT (Fig. 2(a)), larger reduction currents were observed from a similar onset potential of $+0.5 \mathrm{~V}$ vs. Al QRE, while corresponding stripping currents were not observed (see Fig. 2(d)), suggesting that these currents are not due to $\mathrm{Al}$ deposition. It should be noted that a similar reduction current loop with a similar onset potential of $+0.5 \mathrm{~V}$ has been reported for $\mathrm{AlCl}_{3}$-containing organic baths, although it is not clear whether they have the same origin [51].

Consequently, electrodeposition from the G3 and G4 baths was not successful at this point. It seems that $\mathrm{G} 3$ and $\mathrm{G} 4$ have much stronger interactions with $\mathrm{Al}^{3+}$ than $\mathrm{G} 2$, thereby preventing the complexes from being electrochemically reducible to metallic aluminum. A detailed discussion of electrochemically active species is presented below.

\subsection{Stability of Al electrode in the glyme baths}

Figure 3 shows the potential difference between two Al electrodes immersed in the glyme baths. For the G2 bath the potential difference was fairly small for $20 \mathrm{~h}$, with an average 
value of $-1.355 \pm 0.009 \mathrm{mV}$. The long-term stability of the Al electrode in the G2 bath indicates that the redox should be dominated by $\mathrm{Al}^{3+}+3 \mathrm{e}=\mathrm{Al}$ and that the $\mathrm{Al}$ electrode can be utilized as a favorable 'reference electrode of the first kind' [52]. The potential differences for the other glyme baths were not so small as that for G2. Nonetheless, in the G3, G4, and butylG2 baths the $\mathrm{Al}$ electrodes worked as QRE in the $\mathrm{CV}$ experiments, since the potential difference seldom fluctuated in a short period. The origin of the fluctuation of the potential for G3, G4 and butylG2 is not clear at this point. It may be better to use another reference electrode instead of $\mathrm{Al}$, which was directly immersed in the electrolytes. For example, Al immersed in a chloroaluminate ionic liquid, which is separated from the electrolytes by a liquid junction may cause less potential fluctuation, although contamination from the liquid junction could take place.

\subsection{Bath properties at room temperature}

Table II lists the molar conductivities and viscosities of the four kinds of glyme solution at $28{ }^{\circ} \mathrm{C}$. Among them the $\mathrm{G} 2$ bath has the highest conductivity and the lowest viscosity. Nevertheless, the physical properties for the G2, G3 and G4 baths have the same order of magnitude, indicating comparable concentrations of ionic species. In fact, a previous NMR study on G2 and G3 solutions indicated that the ionic species in the G2 bath are four-Cl-coordinated $\mathrm{AlCl}_{4}^{-}$and six-O/Cl-coordinated $\left[\mathrm{AlCl}_{2}(\mathrm{G} 2)_{2}\right]^{+}$, while those in the G3 bath are $\mathrm{AlCl}_{4}^{-},\left[\mathrm{AlCl}_{2}(\mathrm{G} 3)_{n}\right]^{+}$and $\left[\mathrm{AlCl}(\mathrm{G} 3)_{n}\right]^{2+}[50]$. Notably, the six-O/Cl coordination needs at least two G2 molecules because a G2 molecule has only three ether oxygens. The butylG2 bath conductivity is one order of magnitude lower compared to the other baths. 
Because its viscosity is similar to the other values, the low conductivity should be caused by a low concentration of ionic species. Given a specie $\left[\mathrm{AlCl}_{x}(\text { butylG2 })_{n}\right]^{(3-x)+}$ with hexacoordination in the butylG2 bath, at least two molecules are required for complexation in addition to $\mathrm{G} 2$; however, the approach by the oxygen atoms to $\mathrm{Al}^{3+}$ could be hindered due to the terminal butyl chains of butylG2, likely resulting in the low ion concentration.

\subsection{Raman spectroscopy}

In Raman spectroscopy the $\mathrm{CH}_{2}$ rocking and $\mathrm{C}-\mathrm{O}-\mathrm{C}$ symmetric stretching vibration area ranged between $900 \mathrm{~cm}^{-1}$ and $780 \mathrm{~cm}^{-1}$. Figure 4 displays the Raman spectra for the case of G2. It is known that C-O-C vibrations in ethers usually locate between $890-850 \mathrm{~cm}^{-1}$. For the case of free ethers, which are not coordinated by alkaline metal cations, the Raman band is observed at $852 \mathrm{~cm}^{-1}[46,53]$. The Raman band for free $\mathrm{G} 2$ at $852 \mathrm{~cm}^{-1}$ is also seen in the $\mathrm{AlCl}_{3}$-containing $\mathrm{G} 2$ bath, indicating that a sizable amount of free $\mathrm{G} 2$ is still present even in the 1:3 bath. In the case of ethers coordinated by alkaline metal and alkaline earth cations, the Raman band for C-O-C vibration is seen as a blue shift, at $880-890 \mathrm{~cm}^{-1}[46,54,55]$. A shoulder peak appears at around $870 \mathrm{~cm}^{-1}$ by $\mathrm{AlCl}_{3}$ addition, which should correspond to $\left[\mathrm{AlCl}_{2}(\mathrm{G} 2)_{2}\right]^{+}$species as reported from the previous NMR results [50]. The positions of the shoulder peaks are somewhat smaller than those for $\left[\mathrm{Li}(\text { glyme })_{n}\right]^{+}$or $\left[\mathrm{Mg}(\text { glyme })_{n}\right]^{2+}$ in $\mathrm{Li}^{+}$ and $\mathrm{Mg}^{2+}$ amide-glyme solutions [46,54,55], which may be due to the presence of $\mathrm{Cl}$ atoms. Note that the peak at $835 \mathrm{~cm}^{-1}$, which appears by $\mathrm{AlCl}_{3}$ addition, should be assigned as an Al-Cl-G2 complex.

The spectra for the G3 and G4 systems also show shoulder peaks at around $870 \mathrm{~cm}^{-1}$ like 
the G2 system (see the left panel of Fig. 5), strongly indicating that similar Al-Cl-glyme complexes of $\left[\mathrm{AlCl}_{2}(\text { glyme })_{n}\right]^{+}$cations exist and supporting the previous NMR results [50]. For the case of butylG2, the strongest peak is located at $840 \mathrm{~cm}^{-1}$, which differs from those for the $\mathrm{G} 2, \mathrm{G} 3, \mathrm{G} 4$ centered at $850 \mathrm{~cm}^{-1}$, due to the different length of terminal alkyl chains. However, no additional peaks are clearly observed for the $\mathrm{AlCl}_{3}$-containing bath, probably due to the low ion concentration as suggested by the bath properties (see Table II).

In other spectrum regions, Raman spectra for haloaluminate anions are specifically seen between 100 and $400 \mathrm{~cm}^{-1}$ [56]. In the right panel of Fig. 4 the Raman profiles of the G2 baths show a broad peak at $310 \mathrm{~cm}^{-1}$ and three sharp peaks at $120 \mathrm{~cm}^{-1}, 179 \mathrm{~cm}^{-1}$, and 347 $\mathrm{cm}^{-1}$. Although it is reported that $\mathrm{Al}_{2} \mathrm{Cl}_{7}^{-}$shows a peak at $310 \mathrm{~cm}^{-1}$, the observed broad peak is very similar to that in pure $\mathrm{G} 2$, strongly indicating the absence of $\mathrm{Al}_{2} \mathrm{Cl}_{7}^{-}$in the $\mathrm{AlCl}_{3} / \mathrm{G} 2$ bath. Note that the previous NMR results also suggest the absence of $\mathrm{Al}_{2} \mathrm{Cl}_{7}^{-}$[50]. In the right panel of Fig. 5, the spectra for the G3, G4, and butylG2 baths resemble those for the G2 bath in appearance, strongly suggesting that the only anion is $\mathrm{AlCl}_{4}^{-}$. These results afford collateral evidence of the existence of cationic species in the butylG2 bath, even though peaks for cationic species were not clear in the Raman spectra.

\subsection{Electrochemically active species}

It is known that $\mathrm{AlCl}_{4}{ }^{-}$is electrochemically inactive while $\mathrm{Al}_{2} \mathrm{Cl}_{7}^{-}$is active in the case of RT ionic liquids. Since the anionic species in the $\mathrm{G} 2$ bath are $\mathrm{AlCl}_{4}^{-}$, we conclude that cationic species $\left[\mathrm{AlCl}_{2}(\mathrm{G} 2)_{2}\right]^{+}$are electrochemically active. Similarly, in $\mathrm{AlCl}_{3}$-sulfone systems the electrochemically active species are $\left[\mathrm{Al}(\text { sulfone) }]_{3}^{3+}\right.$ cations [56]. The 
sulfone-solvated $\mathrm{Al}^{3+}$ species are generated together with the formation of $\mathrm{AlCl}_{4}{ }^{-}$. Since the resource of $\mathrm{Cl}^{-}$is $\mathrm{AlCl}_{3}$, asymmetric cleavage of $\mathrm{AlCl}_{3}$ occurs to form $\mathrm{AlCl}_{4}^{-}$and $\left[\mathrm{Al}(\text { sulfone })_{3}\right]^{3+}$. In the case of 4-propylpyridine (4-Pr-Py) bath, the asymmetric cleavage of $\mathrm{AlCl}_{3}$ generates $\mathrm{AlCl}_{2}{ }^{+}$and $\mathrm{AlCl}_{4}{ }^{-}$, and the former is coordinated by 4-propylpyridine to produce the Al-containing cations $\left(\left[\mathrm{AlCl}_{2}(4-\mathrm{Pr}-\mathrm{Py})_{2}\right]^{+}\right)[19]$. A similar solvation mechanism should occur with $\mathrm{AlCl}_{3}$-glyme. We also suggest that similar monovalent cationic species (i.e. $\left[\mathrm{AlCl}_{2}(\mathrm{G} 3)_{n}\right]^{+}$and $\left.\left[\mathrm{AlCl}_{2}(\mathrm{G} 4)_{n}\right]^{+}\right)$exist in the $\mathrm{G} 3$ and $\mathrm{G} 4$ baths, although they are not electrochemically active in marked contrast to $\left[\mathrm{AlCl}_{2}(\mathrm{G} 2)_{2}\right]^{+}$. The coordination number is six where two chlorine atoms and four oxygen atoms coordinate to an $\mathrm{Al}^{3+}$ metal center for these monovalent cationic species. As we described above, because a G2 molecule has only three ether oxygens, two G2 molecules are needed to form the hexacoordinated complex (see Fig. 6); for the G3 and G4 complex, by contrast, even a single G3 or G4 molecule can form hexacoordination together with two chlorine atoms, which in turn cause a larger chelating effect or greater stabilization. Therefore, it is natural to consider that the G3 or G4 complex cations are hard to desolvate, resulting in electrochemical inactiveness. The fact that for bath preparation it is harder for $\mathrm{G} 2$ to dissolve $\mathrm{AlCl}_{3}$ than for $\mathrm{G} 3$ and $\mathrm{G} 4$ may also suggest the weaker solvation of G2. Notably, the previous NMR results indicated that cationic species in the $\mathrm{G} 3$ bath include not only monovalent $\left[\mathrm{AlCl}_{2}(\mathrm{G} 3)_{n}\right]^{+}$but also divalent $\left[\mathrm{AlCl}(\mathrm{G} 3)_{n}\right]^{2+}$ cations [50]. Similar divalent complexes could be present in the G4 bath, although no NMR studies for $\mathrm{AlCl}_{3} / \mathrm{G} 4$ have been presented so far. Such divalent G3 and/or G4 complexes would also have difficulty with desolvation, like the monovalent G3 and G4 complexes. 


\subsection{RT electrodeposition of $A l$}

Cathodic deposition was performed potentiostatically at $-2 \mathrm{~V}$ using the $\mathrm{G} 2$ bath for $55 \mathrm{C}$ $\mathrm{cm}^{-2}$. The cathodic current during the deposition was approximately $8 \mathrm{~mA} \mathrm{~cm}^{-2}$, twice as large as that during the deposition at $-1 \mathrm{~V}$ [47]. During electrolysis the G2 bath remained colorless and transparent, indicating that bath decomposition hardly occurred. As shown in Fig. 7(a), black deposits were obtained on $\mathrm{Cu}$ WE, like in the previous report [47]. It should be noted that when the deposits were peeled off using an adhesive tape, the surface contact to $\mathrm{Cu}$ WE substrate exhibited a metallic luster (see Fig. 7(b)).

The XRD measurements shown in Fig. 8 confirmed that the deposits consisted of crystalline $\mathrm{Al}$ metal without trace impurities such as $\mathrm{Al}_{2} \mathrm{O}_{3}$; in the case of potentiostatic electrodeposition at $-1 \mathrm{~V} v s$. Al QRE [47] the XRD profiles also show the deposits were crystalline Al. No preferential orientation was observed. XPS analysis with $\mathrm{Ar}^{+}$etching was conducted for the Al deposits to check the impurity contents and chemical state together with the depth profile. As a result $\mathrm{O}, \mathrm{C}$, and $\mathrm{Cl}$ were detected as the main impurities. Because the inclusion of $\mathrm{Cl}$ is characteristic of coatings electrodeposited from $\mathrm{AlCl}_{3}$-containing electrolytes [17], we focus on $\mathrm{Cl}$. Fig. 9 shows the XPS spectra of the $\mathrm{Cl} 2 \mathrm{p}$ region, where a peak centered at ca. $200 \mathrm{eV}$ was observed. This agrees with the $\mathrm{Cl} 2 \mathrm{p}_{3 / 2}$ binding energies for many chlorides. The $\mathrm{Cl}$ content was about $4 \%$ before etching, and decreased with increasing $\mathrm{Ar}^{+}$etching time, but did not become zero even after etching for $56 \mathrm{ks}$ (ca. 1\%). This confirms that the $\mathrm{Cl}$ was incorporated into the $\mathrm{Al}$ coating during the electrodeposition, and was not a surface contaminant. Notably, after etching the deposits showed a metallic luster. 


\section{Conclusions}

In order to develop relatively safe electrolytes for $\mathrm{Al}$ electrodeposition, a series of $\mathrm{AlCl}_{3}$-containing glyme baths were systematically studied. It was indicated that the ionic species in all glyme baths are $\mathrm{AlCl}_{4}^{-}$and $\left[\mathrm{AlCl}_{2} \text { (glyme) }\right)_{n}^{+}$, but only the $\mathrm{G} 2$ complex is electrochemically reducible to metallic aluminum due to the easy desolvation of G2. This strong dependence on the type of glymes seems specific to Al electroplating, and contrasts with lithium and magnesium electrodeposition [41-46]. Potentiostatic electrodeposition results using the $\mathrm{G} 2$ bath demonstrated that the coatings electrodeposited at as low as $-2 \mathrm{~V} v s$. Al QRE were essentially composed of a single phase of Al metal, although XPS indicated that $\mathrm{Cl}$ was incorporated in the states of chloride. However, the absence of a black appearance by $\mathrm{Ar}^{+}$etching suggests that the black appearance was caused by the surface 
1

2

3

4

5

7

8

morphology, i.e., a rough surface, and was not due to impurities. Further studies on $\mathrm{AlCl}_{3} /$ glyme baths such as bright and/or flat electrodeposition using additives are of special interest.

\section{Acknowledgments}

We thank Y. Sonobayashi and Y. Uno for their experimental help in XPS measurements. This work was financially supported by Grant-in-Aid for Scientific Research (A) (No. 25249106 and No. 16H02411), Grant-in-Aid for challenging Exploratory Research (No.15K14193), and Grant-in-Aid for Young Scientists (B) (No. 15K18253) from the Japan Society for the Promotion of Science (JSPS). A.K also thanks Iketani Science and Technology Foundation for their financial support (No. 0271016-A). 


\section{References}

1. A. R. Brukin, Production of Aluminium and Alumina, Critical Reports in Applied Chemistry, Vol. 20. John Wiley, Chichester, U.K. (1987).

2. Y. Zhao, T. J. VanderNoot, Electrochim. Acta, 41 (1997) 3.

3. D. E. Couch, A. Brenner, J. Electrochem. Soc., 99 (1952) 234.

4. N. Ishibashi, M. Yoshio, Electrochim. Acta., 17 (1972) 1343.

5. E. Peled, E. Gileadi, J. Electrochem. Soc., 123 (1976) 15.

6. M. Chiku, H. Takeda, Y. Yamaguchi, E. Higuchi, H. Inoue, Int. J. Chem., 5 (2013) 1.

7. C. A. Capuano, W. G. Davenport, J. Electrochem. Soc., 118 (1971) 1688.

8. C. A. Capuano, W. G. Davenport, Plating, 60 (1973) 251.

9. K. Ziegler, H. Lehmkuhl, Z. Anorg. Allg. Chem., 283 (1956) 414.

10. J. P. Pereira-Ramos, R. Messina, J. Perichon, J. Electroanal. Chem., 209 (1986) 283.

11. L. Legrand, A. Tranchant, R. Messina, Electrochim. Acta, 39 (1994) 1427.

12. L. Legrand, A. Tranchant, R. Messina, J. Electrochem. Soc., 141 (1994) 378.

13. L. Legrand, M. Heinz, A. Tranchant, R. Messina, Electrochim. Acta, 40 (1995) 1711.

14. J. Fransaer, E. Leunis, T. Hirato, J.-P. Celis, J. Appl. Electrochem., 32 (2002) 123.

15. T. Jiang, M. J. Chollier Brym, G. Dube, A. Lasia, G. M. Brisard, Surf. Coat. Technol., 201 (2007) 6309.

16. S. Shiomi, M. Miyake, T. Hirato, J. Electrochem. Soc., 159 (2012) D225. 
17. M. Miyake, H. Motonami, S. Shiomi, T. Hirato, Surf. Coat. Technol., 206 (2012) 4225.

18. M. Miyake, S. Tajikara, T. Hirato, Surf. Coat. Technol., 205 (2011) 5141.

19. Y. X. Fang, K. Yoshii, X. G. Jiang, X. G. Sun, T. Tsuda, N. Mehio, S. Dai, Electrochim. Acta, 160 (2015) 82.

20. A. Endo, M. Miyake, T. Hirato, Electrochim. Acta, 137 (2014) 470.

21. F. H. Hurley, T. P. Wier Jr., J. Electrochem. Soc., 98 (1951) 203.

22. R. T. Carlin, W. Crawford, M. Bersch, J. Electrochem. Soc., 139 (1992) 2720.

23. J. Robinson, R. A. Osteryoung, J. Electrochem. Soc., 127 (1980) 122.

24. P. K. Lai, M. S. Kazacos, J. Electroanal. Chem., 248 (1988) 431.

25. T. Tsuda, T. Nohira, Y. Ito, Electrochim. Acta, 47 (2002) 2817.

26. T. Tsuda, C. L. Hussey, Thin Solid Films, 516 (2008) 6220.

27. A. P. Abbott, G. Frisch, K. S. Ryder, Ann. Rev. Mater. Res., 4343 (2013) 335.

28. J-P. M. Veder, M. D. Horne, T. Rüther, A. M. Bond, T. Rodopoulos, Electrochem. Commun. 18 (2012) 85.

29. J-P. M. Veder, M. D. Horne, T. Rüther, A. M. Bond, T. Rodopoulos, Electrochem. Commun. 37 (2013) 68.

30. S. J. Pan, W. T. Tsai, J. K. Chang, I. W. Sun, Electrochim. Acta, 55 (2010) 2158.

31. H. Yang, X. Guo, G. Wu, W. Ding, N. Birbilis, Corros. Sci., 53 (2011) 381.

32. B. Xu, M. Zhang, G. Ling, Surf. Coat. Technol., 239 (2014) 1.

33. M. Miyake, H. Fujii, T. Hirato, Surf. Coat. Technol., 277 (2015) 160.

34. N. Jayaprakash, S. K. Das, L. A. Archer, Chem. Commun., 47 (2011) 12610.

35. L. D. Reed, E. Menke, J. Electrochem. Soc., 160 (2013) A915. 
36. J. V. Rani, V. Kanakaiah, T. Dadmal, M. S. Rao, S. Bhavanarushi, J. Electrochem. Soc., 160 (2013) A1781.

37. M.-C. Lin, M. Gong, B. Lu, Y. Wu, D.-Y. Wang, M. Guan, M. Angell, C. Chen, J. Yang, B.-J. Hwang, H. Dai, Nature, 520 (2015) 324.

38. T. Tsuda, I. Kokubo, M. Kawabata, M. Yamagata, M. Ishikawa, S. Kusumoto, A. Imanishi, S. Kuwabata, J. Electrochem. Soc., 161 (2014) A908.

39. M. Chiku, H. Takeda, S. Matsumura, E. Higuchi, H. Inoue, ACS Appl. Mater. Interfaces, 7 (2015) 24385.

40. Y. Nakayama, H. Kawasaki, H. Morioka, U.S. Patent 20,150,280,279 (2015).

41. T. Tamura, T. Hachida, K. Yoshida, N. Tachikawa, K. Dokko, M. Watanabe, J. Power Sources, 195 (2010) 6095.

42. S.-Y. Ha, Y.-W. Lee, S. W. Woo, B. Koo, J.-S. Kim, J. Cho, K. T. Lee, N.-S. Choi, ACS Appl. Mater. Interface, 6 (2014) 4063.

43. Y. Orikasa, T. Masese, Y. Koyama, T. Mori, M. Hattori, K. Yamamoto, T. Okado, Z.-D. Huang, T. Minato, C. Tassel, J. Kim, Y. Kobayashi, T. Abe, H. Kageyama, Y. Uchimoto, Sci. Rep., 4 (2014) 5622.

44. T. Fukutsuka, K. Asaka, A. Inoo, R. Yasui, K. Miyazaki, T. Abe, K. Nishio, Y. Uchimoto, Chem. Lett., 43 (2014) 1788.

45. A. Kitada, Y. Kang, Y. Uchimoto, K. Murase, J. Electrochem. Soc., 161, (2014) D102.

46. A. Kitada, Y. Kang, K. Matsumoto, K. Fukami, R. Hagiwara, K. Murase, J. Electrochem. Soc., 162 (2015) D389.

47. A. Kitada, K. Nakamura, K. Fukami, K. Murase, Electrochemistry, 82 (2014) 946. 
48. T. Mandai, P. Johansson, J. Mater. Chem. A, 3 (2015) 12230.

49. L. D. Reed, A. Arteaga, E. J. Menke, J. Phys. Chem. B, 119 (2015) 12677.

50. H. Nöth, R. Rurländer, P. Wolfgardt, Z. Naturforsch, B: Chem. Sci. 37B (1982) 29.

51. Y. Fang, X. Jiang, X-G Sun, S. Dai, Chem. Commun., 51 (2015) 13286.

52. K. Izutsu, "Electrochemistry in Nonaqueous Solutions," Wiley-VCH, WeinHeim, 2002, pp. $167-175$.

53. T. Mandai, R. Nozawa, S. Tsuzuki, K. Yoshida, K. Ueno, K. Dokko, M. Watanabe, J. Phys. Chem. B, 117 (2013) 15072.

54. J. C. Lassègues, J. Grondin, D. Talaga, Phys. Chem. Chem. Phys., 8 (2006) 5629.

55. J. Grondin, J. C. Lassègues, M. Chami, L. Servant, D. Talaga, W. A. Henderson, Phys. Chem. Chem. Phys., 6 (2004) 4260.

56. L. Legrand, A. Tranchant, R. Messina, F. Romain, A. Lautie, Inorg. Chem. 35 (1996) 1310. 
Table I. Bath properties of the $\mathrm{G} 2$ bath with the molar ratio of $\mathrm{AlCl}_{3}: \mathrm{G} 2=1: 5$ at several temperatures.

Table II. Bath properties of the glyme baths at $28^{\circ} \mathrm{C}$ with the molar ratio of $\mathrm{AlCl}_{3}: \mathrm{glyme}=$ $1: 5$ 
Figure 1. Schematic structure of glymes used in this study.

Figure 2. CVs with sweep rate of $20 \mathrm{mV} \mathrm{s}^{-1}$ in $\mathrm{AlCl}_{3}$-dissolved glyme solution with $\mathrm{AlCl}_{3}$ :glyme = 1:5 by mol, under the condition of (a) $\mathrm{Cu}$ WE at RT, (b) Al WE at RT, (c) Cu WE at several temperatures, and (d) $\mathrm{Cu} \mathrm{WE}$ at $60^{\circ} \mathrm{C}$.

Figure 3. Time change in potential difference between two $\mathrm{Al}$ electrodes immersed in the glyme at $\mathrm{RT}$ with molar ratio of $\mathrm{AlCl}_{3}:$ glyme $=1: 5$. Dashed line indicates zero line.

Figure 4. Raman spectra for the $\mathrm{AlCl}_{3}: \mathrm{G} 2=1: 3$ and $1: 5$ by mol, and pure $\mathrm{G} 2$ obtained between $900 \mathrm{~cm}^{-1}$ and $780 \mathrm{~cm}^{-1}$ (left panel) and between $400 \mathrm{~cm}^{-1}$ and $100 \mathrm{~cm}^{-1}$ (right panel). Dashed lines emphasize specific peaks for $\mathrm{Al}^{3+}-\mathrm{G} 2$ complex, pure $\mathrm{G} 2$ and $\mathrm{AlCl}_{4}^{-}$.

Figure 5. Raman spectra for the $\mathrm{AlCl}_{3}:$ glyme = 1:3 and pure glyme obtained between 900 $\mathrm{cm}^{-1}$ and $780 \mathrm{~cm}^{-1}$ (left panel) and between $400 \mathrm{~cm}^{-1}$ and $100 \mathrm{~cm}^{-1}$ (right panel). Dashed lines emphasize specific peaks for $\mathrm{Al}^{3+}$-glyme complex, pure glyme and $\mathrm{AlCl}_{4}{ }^{-}$.

Figure 6. Possible schematic structures of $\left[\mathrm{AlCl}_{2}(\text { glyme })_{n}\right]^{+}$complexes for the case of G2 (top), G3 (middle), and G4 (bottom). 
Figure 7. Photographs of the $\mathrm{Cu}$ WE electrodeposited from the $\mathrm{G} 2$ bath at $-2 \mathrm{~V} v s$. Al QRE: (a) obverse side and (b) reverse side, which appeared by peeling off the deposits with an adhesive tape.

Figure 8. XRD profiles of the electrodeposits obtained at $-2 \mathrm{~V} v s$. Al QRE.

Figure 9. XPS spectra of the Al electrodeposits obtained at $-2 \mathrm{~V}$ vs. Al QRE.

Figure 10. (a) Top view and (b) cross-sectional view of the SEM images for the Al deposits obtained at $-2 \mathrm{~V} v s$. Al QRE. 
Temperature

\section{Conductivity Viscosity $\left(\mathrm{mS} \mathrm{cm}^{-1}\right)$ \\ (mPa s)}
$28^{\circ} \mathrm{C}$
4.08
2.92
$40{ }^{\circ} \mathrm{C}$
4.48
2.67
$50{ }^{\circ} \mathrm{C}$
5.53
2.35
$60^{\circ} \mathrm{C}$
6.48
2.03 
Electrolyte

\section{Conductivity Molar conductivity Viscosity

$$
\left(\mathrm{mS} \mathrm{cm}^{-1}\right) \quad\left(\mathrm{S} \mathrm{cm}^{2} \mathrm{~mol}^{-1}\right) \quad(\mathrm{mPa} \mathrm{s})
$$

$\begin{array}{llll}\text { G2 } & 4.08 & 2.92 & 2.71 \\ \text { G3 } & 2.07 & 1.88 & 4.54 \\ \text { G4 } & 1.10 & 1.14 & 6.24 \\ \text { utyl G2 } & 0.16 & 0.19 & 5.42\end{array}$

butyl G2

0.16

5.42 


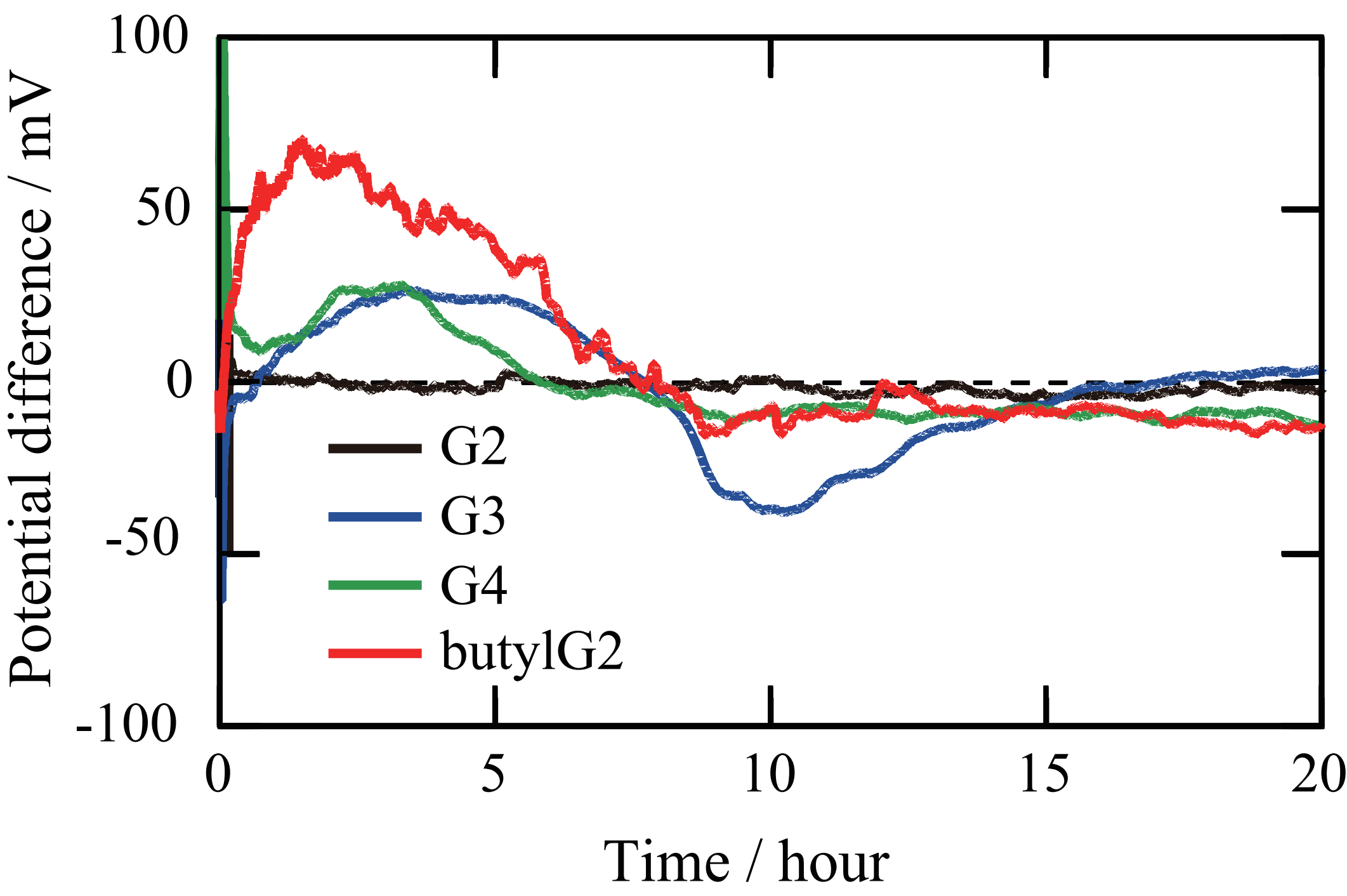




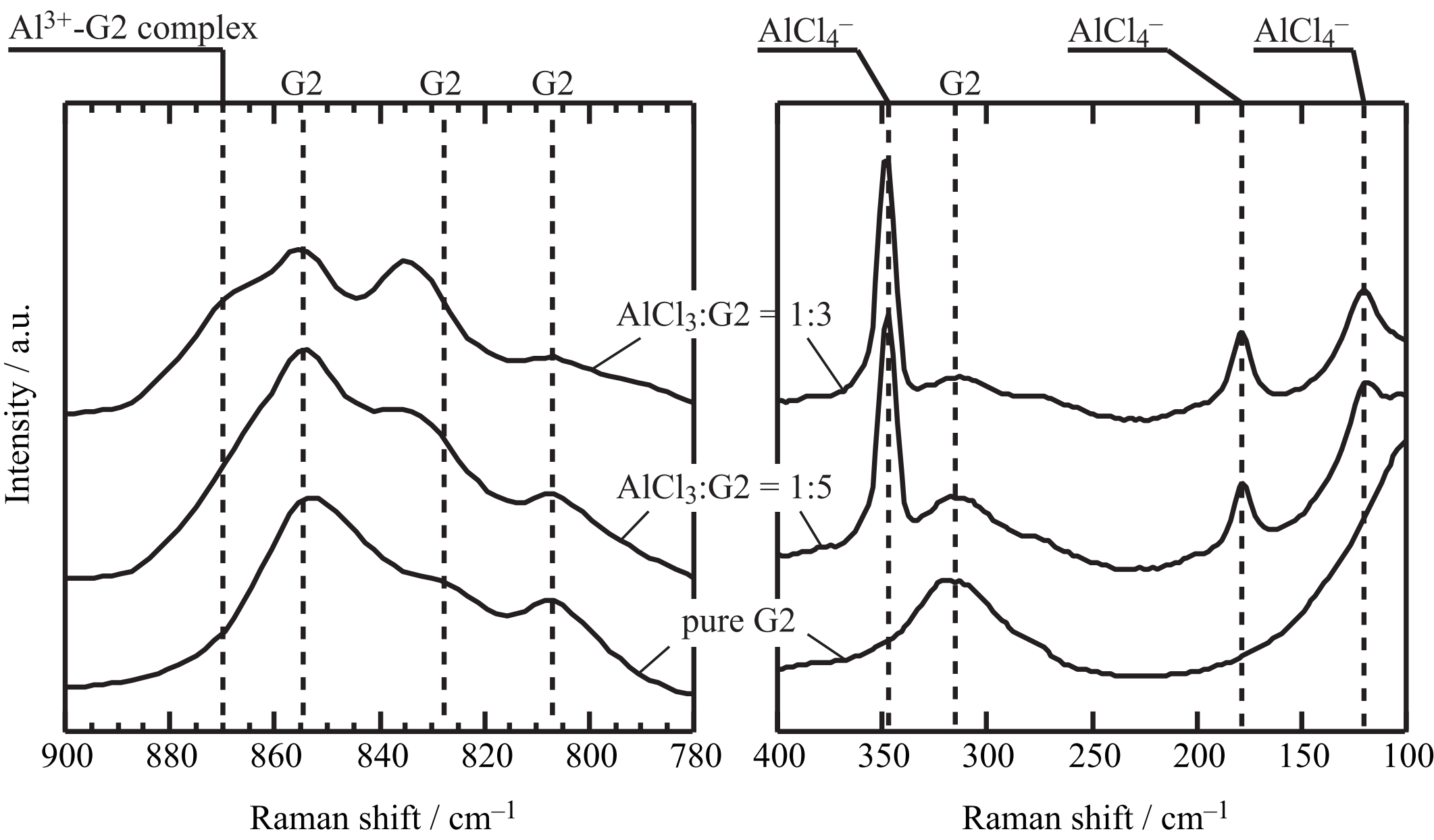


$\mathrm{Al}^{3+}{ }^{3+}$-glyme complex pure Glyme

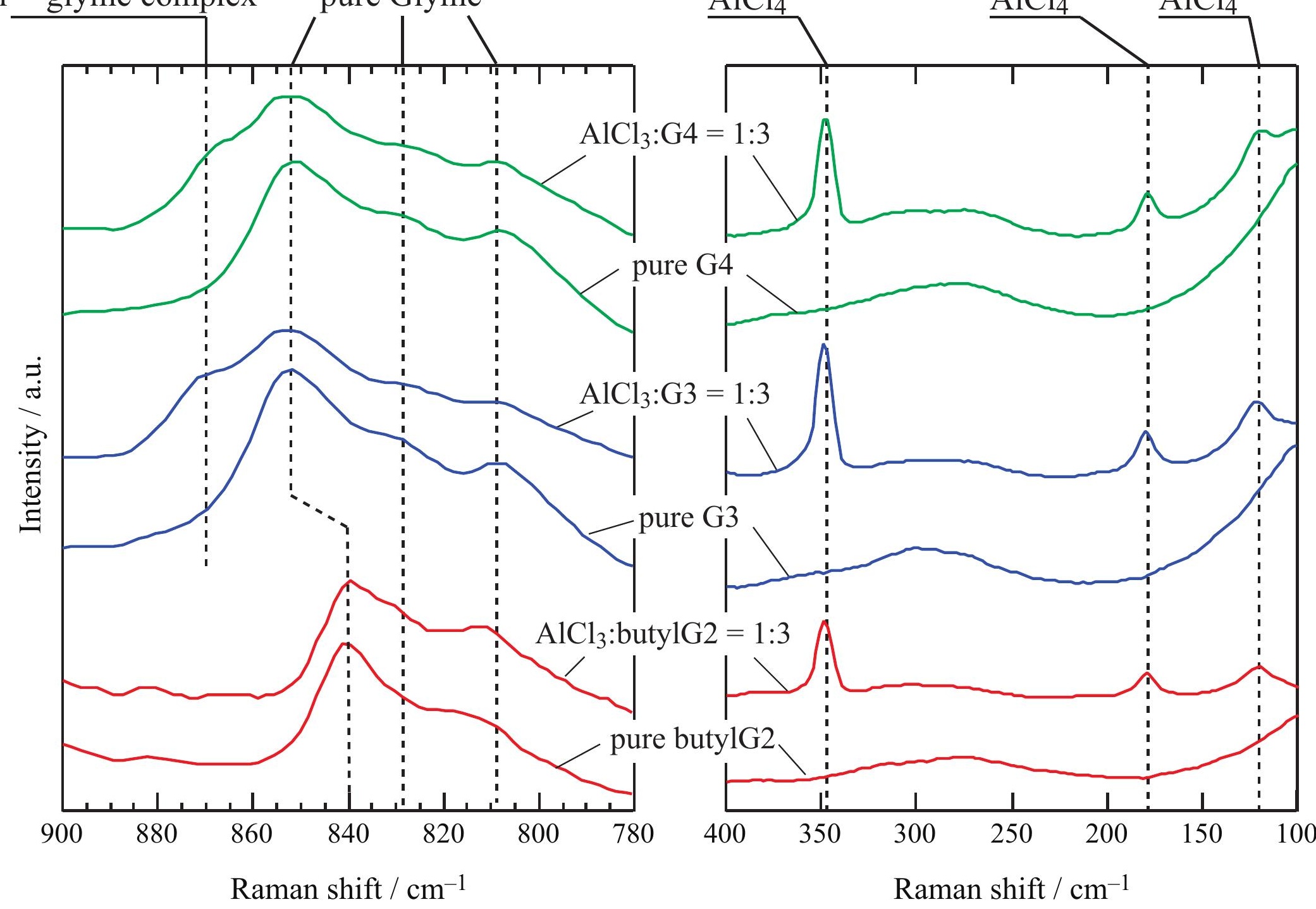


G3
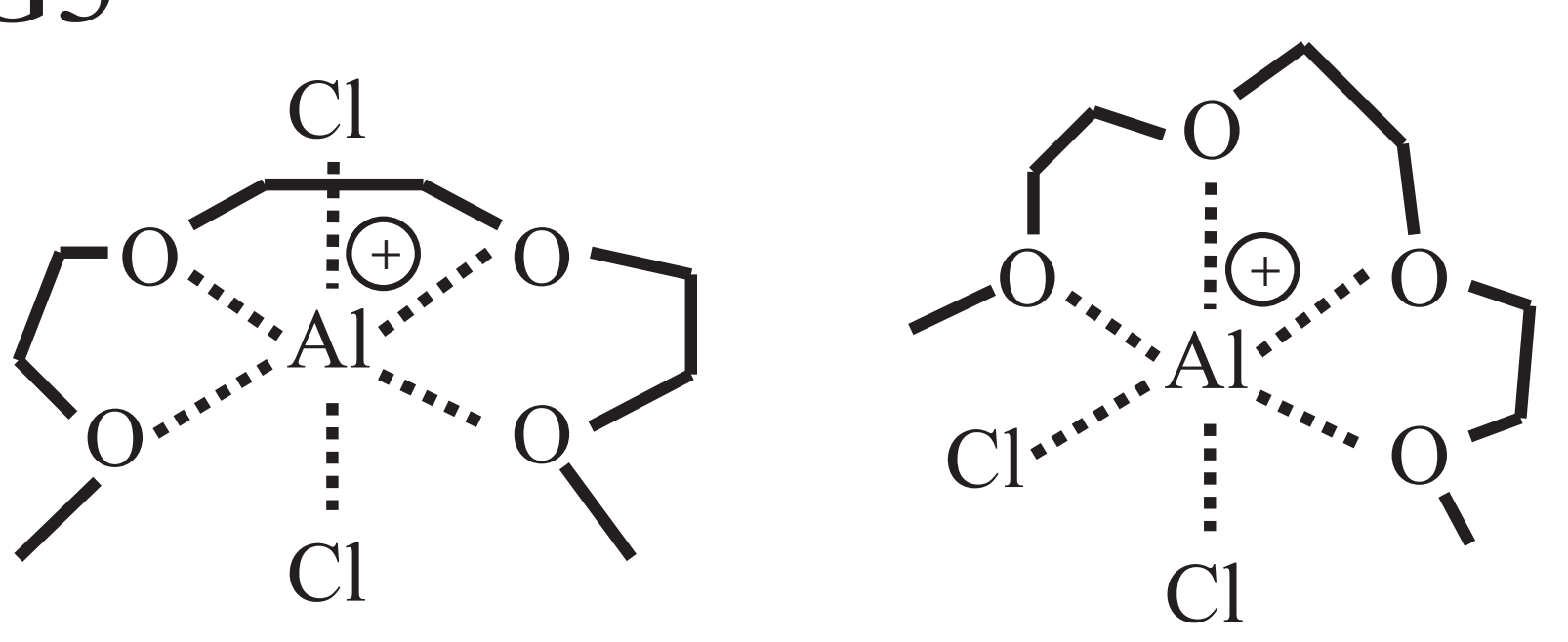

G4
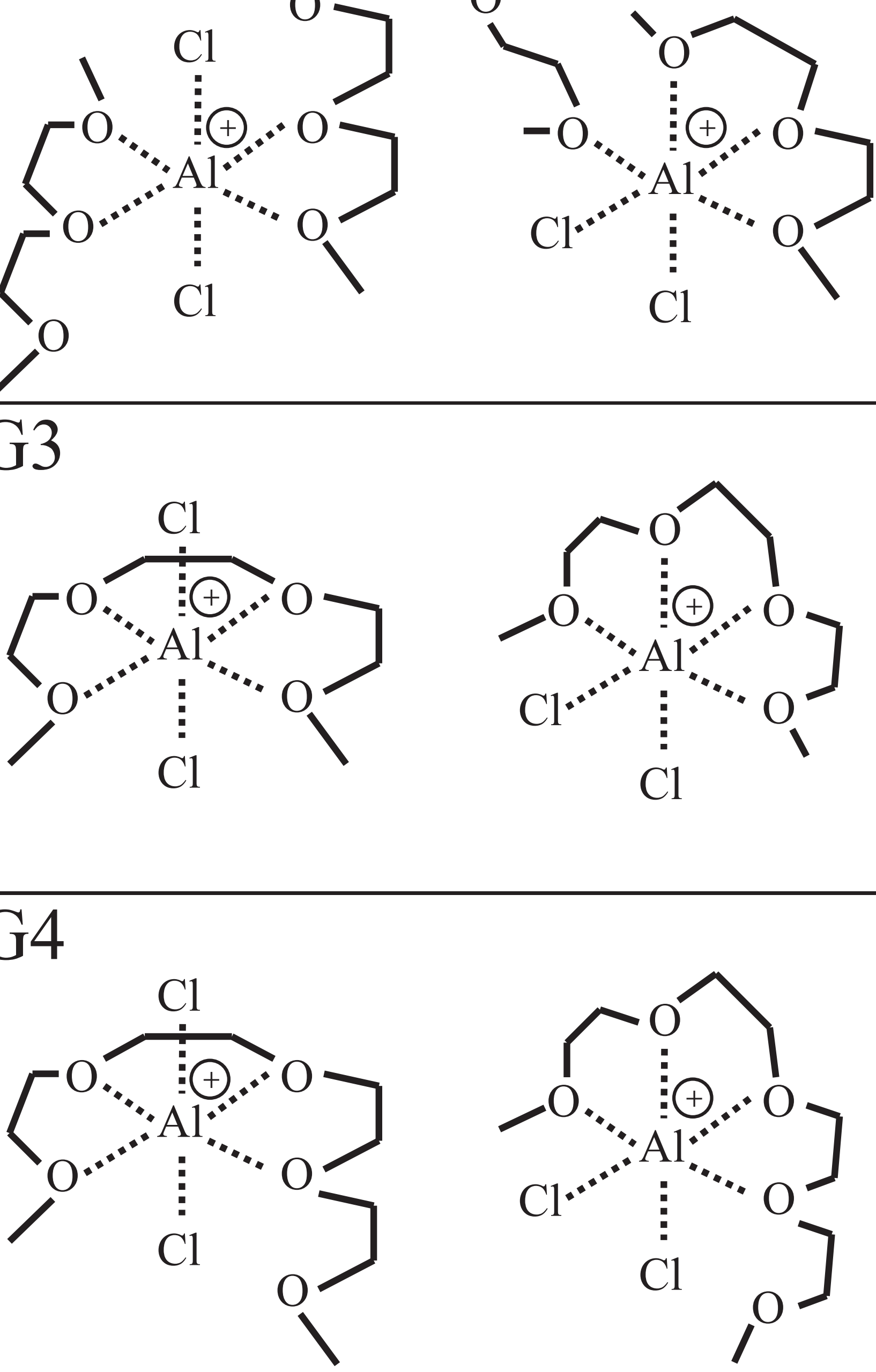

0

$\mathrm{Cl}$

$\mathrm{O}$ 


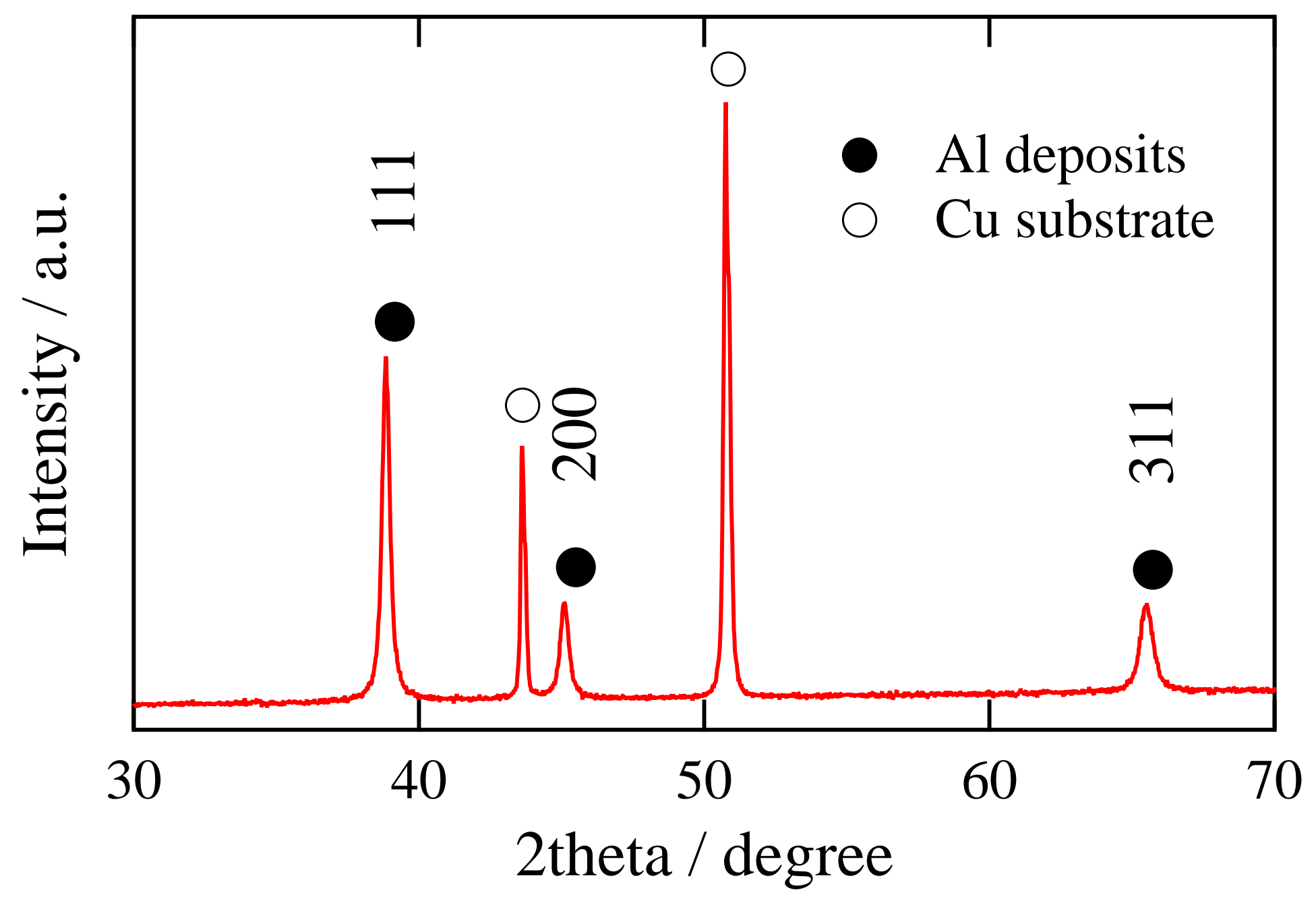





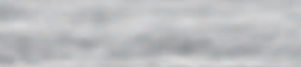

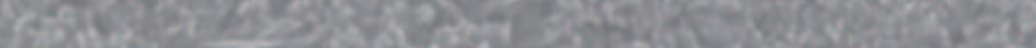

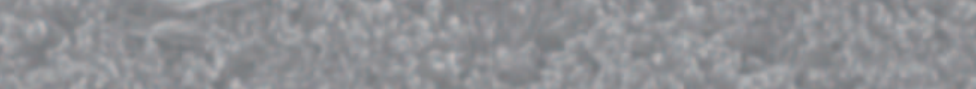

